\title{
Usability Evaluation of Web Search User Interfaces from the Elderly Perspective
}

\author{
Khalid Krayz Allah, Nor Azman Ismail, Layla Hasan, Wong Yee Leng \\ School of Computing, Faculty of Engineering \\ Universiti Teknologi Malaysia Johor, Malaysia
}

\begin{abstract}
The elderly population is increasing in many countries, often with health and incapacity challenges, largely disengaged them from the world of digital tools like Internet usage. They browse the Internet daily for obtaining needed information through various search engines through the search UI. Earlier technologies were fabricated for improving daily life, but the specific needs of the elderly are neglected often. Currently, available online search UIs are well-developed, but they did not consider usability in their design specifically for the elderly. This research aims to evaluate web search UIs based on the elderly perspectives to identify existing search UIs usability issues and recommend improvements to web search UI designs. The observation technique evaluated two web search UIs (Google interface and Bing interface) with fifteen participants aged 60 years and above. System Usability Scale (SUS) questionnaire was applied to measure the user satisfaction of the current two interfaces. The data collected from the observations were analyzed using content analysis, while the data acquired from the questionnaires were analyzed using the t-test. The results revealed a statistically significant difference in SUS ratings, with Google scoring 73.5 and Bing scoring 66.5, indicating that users prefer the Google interface over the Bing interface. Besides that, the usability issues were identified, and recommendations to improve the design of the search UI were suggested. These findings contribute to a better understanding of the issues that prevent elderly users from using web search UI and valuable feedback to designers on improving the UI to suit the elderly better.
\end{abstract}

Keywords-Usability; Google interface; Bing interface; SUS questionnaire; web search user interfaces; observation method

\section{INTRODUCTION}

The number of elderly people is increasing rapidly in most of the countries in the world as well as their use of the Internet is also increasing [1, 2]. They use the Internet daily for searching various information, mostly via search engines. Due to the growth and impact of information technology in our dayto-day life, one should need to gather more information from the websites. So, searching on the Internet is an important cognitive process to find out the needs of different kinds of resources to achieve their aim [3]. The search UI is the way to communicate and interact the users with search engines to acquire the desired information [4]. Although research on estimation models based on web search logs aims to improve our daily lives, the needs of the elderly are frequently overlooked [5]. Those designs may be challenging to learn and use for elderly people. Researchers are looking at the web search activity for the usage of elders in professional and business domains as a result of this trend.
Furthermore, the user interface (UI) is considered to be an important component of any interactive software system from the users' perspective because it is the most visible front-end component through which the users could see and work with and perform primary evaluation while utilizing the system [6, 7]. As a result, the needs of users in system development would lead to effective user interfaces and useable collaborative systems. Alternatively, the bad user interface design would cause a greater challenge for the users. Yet, there is no clear evidence that poor user interface design is very much challenging.

The exposure to web search for the elderly user is less because of the cognitive functions that reduce due to age [8]. Both elderly and younger ones have some search strategies to use their knowledge and skills. The elderly person searches very little but attains more appropriate information and performs well by acquiring better results [8, 9]. However, elderly users cannot adapt to a newer searching strategy and change their search pattern or style even for highly challenging search tasks $[9,10]$. Also, elderly users have physical problems like visual impairment, colour identification etc., cognitive impairment, knowledge about computers and technologies [10].

Usability is an essential key factor for the software developers or users, as it ensures the successiveness of the system and its further development by focusing on the needs and requirements of the users $[11,12]$. Usability, according to ISO 9241 [13], is defined as the absence of usability difficulties or the measuring of efficiency, effectiveness and satisfaction. Usability is contingent on the absence of usability issues. The main concern of users is the usability of the software and the consequences of utilizing it without the knowledge of the systems core components, it is working, or its production [14]. While developing software, the needs of the users must be considered and given careful consideration.

Various usability evaluation methods were developed, which comprises a set of techniques for evaluating the usability of the systems user interface and identifying specific issues [15, 12]. In general, usability evaluation methods can be categorized into expert-based and user-based [8, 9].

Expert-based techniques, often called inspection methods, involve experts evaluating the user interface and identifying potential issues that users might encounter while interacting [16]. Such studies can result in a formal report highlighting problems or making suggestions for improvements [17]. The heuristic evaluation method and cognitive walkthrough 
method are the two most commonly utilized expert-based usability approaches in the area of human interaction [18].

User-based techniques, as well known as test methods, are useful evaluation methods for obtaining information about real users' behaviours as well as finding and identifying usability issues by noticing people that represent users be using on the system interface $[9,10]$. User-based techniques are used to see how well a system assists the end-user with their tasks [8]. Empirical or experimental techniques, methods used in this study, query methods, and physiological monitoring methods, such as gaze and heart rate and skin conductance measurements, are all extensively used in the field of human-computer interaction among the various approaches that are based on the users [18].

Several earlier studies evaluated the usability of search UIs based on user-based methods for elderly people [19, 20, 21, 22]. Furthermore, there seems to be a scarcity of research that assesses the usability of search engine UIs and offers particular changes to their design to make them easier to use by the elderly.

This research aims to evaluate the usability of web search UIs from elderly users' perspectives to uncover the usability issues on these UIs, and based on the results to suggest specific recommendations for usable web search UIs for elderly people.

The specific objectives of this research are:

1) To use observational techniques to identify usability issues on two common web search user interfaces; Google and Bing.

2) To use the System Usability Scale (SUS) questionnaire to measure the user satisfaction of the two web search user interfaces (Google interface and Bing interface).

3) To identify additional user requirements that could aid in creating a proposed design for the newly designed UI for the elderly group.

4) To recommend specific improvements to design usable web search user interfaces for elderly users.

The results of this research will uncover challenges on the search UIs from the perspectives of elderly users and would reflect the requirements to conduct the improvements process to meet users' needs and requirements. This will enhance the ease of use of web searching by the elderly community and provide information to web search interface designers about possible improvements for designing a user-friendly search user interface for elderly users.

This research is divided into six sections. Section II presents earlier studies that evaluated the usability of web search user interfaces for elderly users. The methodology is presented in Section III. Section IV presents the results, while Section V presents the discussion. Finally, in Section VI, the conclusion is outlined.

\section{USABILITY EVALUATION FOR THE ELDERLY}

The literature showed that research had been done to evaluate the usability of desktop or laptop user interfaces for elderly people. Many studies have been published that employed usability testing to evaluate the usability of websites and smartphone user interfaces for elderly users using representative user groups [19 - 23]. Specifically, Patsoule and Koutsabasis conducted a comparative usability evaluation of two websites where the participants with 12 older adults aged 65 years and over [24]. Controlled usability testing, as well as post hoc interviews and questionnaires, were employed to assess their performance on six standardized activities. The rebuilt website was far more functional and acceptable than the previous version [24].

In addition, Haesner et al. (2018) conducted a usability test with older users to analyze the usability and acceptance of Google Glass [25]. The participants were 30 elders aged 65 and up who were requested to complete a set of standardized tasks and evaluate usability using a system usability scale questionnaire in order to acquire valuable information into specific usability difficulties. The final findings revealed that usability should be considered while developing mobile applications for elderly people by using Google Glass [25].

Alternatively, there have been a number of user evaluation studies of web search UIs based on user-based methods [19, 20.21,22]. Sanchiz et al. (2019) used eye-tracking metrics to test 9 search issues using standard web browsers and/or empirical search interfaces. The final empirical findings showed that older adults spend significantly more time on search engines than younger adults [4].

More specifically, Aula et al. $[19,26]$ have conducted two usability tests to compare the usability of Etsin, a friendly search engine for the elderly, and Google by giving search tasks to elderly users. The observation method was used to monitor the elderly's interacting behavior during the search tasks, followed by an interview to find all usability problems of web user interface engines. The results identified age-related issues in the search UIs that should be taken into account, which are beneficial to elderly users. For example, the search engine interface should be a simple one that is easy to use and understand.

\section{ReseARCH Methodology}

This study is conducted in three phases: usability testing, evaluation, and analyzing and interpreting data, as shown in Fig. 1. To achieve the objectives of this research, two usability testing methods were employed: observation and System Usability Scale (SUS) questionnaire. This section consists of five sub-sections which describes: the methods employed in this research, participants, apparatus, the procedure of the testing, and the analysis of the collected data.

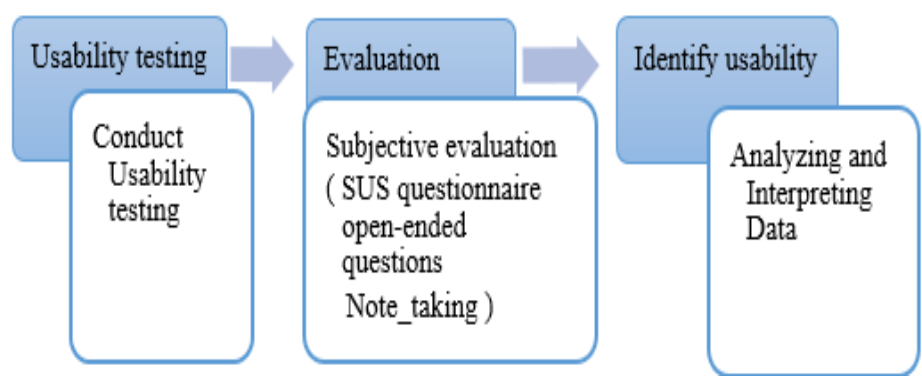

Fig. 1. Three Main Phases of the Methodology. 


\section{A. Methods}

1) Observation and note-taking: Observing how users interact with a system is a common technique to learn more about its use. This technique tries to monitor participants while they utilize the web search user interface to conduct their searches. Taking notes during the usability test, these participants' reactions to the challenges they encounter while engaging with the system are also recorded [19, 22, 26]. Conducting a usability test is the most effective way to obtain high-quality qualitative data by observing the interface and users' reactions to the task, which allows the practitioner to quickly identify system design flaws $[27,28]$. As a result, the practitioner observed the participants throughout the sessions and took notes. As a result, users are encouraged to "think aloud" about their actions [29].

In this research, observers were employed to take notes and observe the participation behaviors while interacting with the interfaces during the usability test.

2) System usability scale (SUS): The system usability scale (SUS) is a popular tool among HCI researchers for assessing perceived usability in both usability and survey research [30, 31, 32]. According to reports, the SUS was used in $43 \%$ of usability studies [33, 34]. Furthermore, a study that evaluated SUS discovered a valid and reliable tool for evaluating usability [34, 35]. The SUS is a ten items questionnaire with alternating positive and negative statements and a five-point Likert scale spanning from strongly disagree to strongly agree in ascending order designed to avoid answer biases. These ten items will be assessed, and a final score ( 0 100) will be determined by grading them from A to F or using adjective ratings. Bangor Different SUS grade rankings are presented by Kortum and Miller [36]. Before 2009, the SUS study was only focused on perceived usability (unidimensional). However, Lewis and Sauro [34, 37] suggested that the SUS is a bi-dimensional measure (usability and learnability sub-scales) in 2017. If the research situation is convenient and the participants are experienced, the SUS was advised in employing bi-dimensional analyses [37, 38]. Furthermore, according to Tullis and Stetson [34, 39], SUS allows researchers to test perceived usability with a small sample size of 8-12.

In this study, bi-dimensional and unidimensional analyses of the SUS scale were undertaken due to the diverse backgrounds of the participants.

\section{B. Participates}

The participants were recruited from elderly homes and through personal contacts. The participants in the study were given a feedback form with demographic information and questions regarding their computer and Internet search experience.

\section{Apparatus}

Windows operating system ten was utilized by all of the participants in the search sessions. Only nine users used
Chrome to access the Google interface, while six used Mozilla Firefox to access the Bing interface. The monitors were identical in size and resolution (1024 x 768 on a 15-inch panel).

\section{Procedure}

At the start of the usability evaluation, all of the participants were told that the study was all about finding facts on the Internet and gathering data on how useful the interface is. They were also told that throughout the test session, they might run into some difficulties with a specific test task in which they don't have to worry, and if they feel difficult to finish it, then they can just say that it is difficult to continue and would like to stop, and can move on to the next task. They were also promised that if they typed text into the text field, the search engine would return any publications that contained the text or all the text they had entered. Before the test began, the participants signed a document indicating their consent to participate in the testing as well as the recording and reporting of their responses for the study.

All of the participants were given a sequence of seven search tasks containing a variety of interests. They were also instructed to conduct relevant searches on those topics using the Google and Bing search engines. They were then invited to ask the first question for the job of their choice and then proceed with the activity normally. The participants utilized the computer on their own during the search phase. They were, however, able to ask questions and receive assistance if needed during the search.

The search session was for 20-30 minutes. During the session, observers were present to take note of the participants' reactions while using the search engine. After the participants searched in the search engine, all the participants were given a questionnaire having a set of questions about the interface they have worked on to detect usability issues and additional users' requirements. The questions were intended in such a way that it uses the SUS questionnaire for UI satisfaction [18, 40]. The satisfaction of the participants is measured on a scale of 5points. The questions include the overall reaction to the web search interface. Two open-ended questions allowed the participants to write down the positive and the negative feedback about the interface in their point of view. These questions provide valuable information about the interface design in addition to the statistical data. Finally, to make it easier to relate the interfaces, they were shown both of them simultaneously with the different questions with the same meaning.

\section{E. Analyzing and Interpreting Data}

Following the sessions, the observers went through their notes and the questionnaires to flesh out the usability issues, mostly experienced by more than eight of the fifteen participants for each search UI. During the search, the participants' verbalizations and behaviours were recorded. Following that, a list of usability issues for each interface was developed. Finally, the common usability issues and participant behaviour observations found in both the Google engine interface and the Bing engine interface were assembled. 


\section{RESULTS}

\section{A. Participants' Characteristics}

A total of 15 people volunteered in this study, eight male (53\%) and seven female (47\%). All of the participants were above 60 years old, with an average age of 62.5 years for males and 61.5 years for females. The age ranges from 60 to 67 years for males and from 60 to 65 years for females. The demographic information of the participants is summarized in Table I. All of the participants used computers in their daily lives when it came to searching the Internet, with an average experience of 9 years (3 to 10 years). The majority of male participants utilized the Internet to search on a regular basis, while female participants had an average experience of 4 years (2 to 7 years). Most of the participants had previous experience with search engines like Bing, Google, and MSN Search, where the others are rookie searchers who are mostly directed to facts from well-known URLs, if at all.

TABLE I. THE PARTICIPANTS' INFORMATION

Participates sample characterization

\begin{tabular}{|l|l|l|}
\hline Gender & Male, $8(53 \%)$ & Female, $7(47 \%)$ \\
\hline Mean Age & 62.5 & 61.57 \\
\hline Mean Experience & 6 years & 4 years \\
\hline
\end{tabular}

\section{B. Qualitative Results}

This sub-section presents the qualitative results obtained from the content analysis of the observation and note-taking methods and the questionnaire's open-ended questions. It shows the major problems that the elderly users faced while interacting with both interfaces, which provide important information about their perspectives and experiences. The collected data were transcribed as clear data, as shown in Table II.

TABLE II. USABILITY PROBLEMS IDENTIFIED FROM THE QUALITATIVE RESULTS

\begin{tabular}{|l|l|l|}
\hline Usability Problems & $\begin{array}{l}\text { Google } \\
\text { Interface }\end{array}$ & $\begin{array}{l}\text { Bing } \\
\text { Interface }\end{array}$ \\
\hline $\begin{array}{l}\text { The default font size is small. Also, the font size } \\
\text { varies from one browser to another. }\end{array}$ & $\checkmark$ & $\checkmark$ \\
\hline $\begin{array}{l}\text { The voice search button, the image search button } \\
\text { and the text search button are small and close to } \\
\text { each other. }\end{array}$ & $\checkmark$ & $\checkmark$ \\
\hline $\begin{array}{l}\text { Difficult to go back to bookmark and history in } \\
\text { different browsers }\end{array}$ & $\checkmark$ & $\checkmark$ \\
\hline A large number of results & & $\checkmark$ \\
\hline $\begin{array}{l}\text { Misunderstanding suggested results such as People } \\
\text { Also Search For and Related Searches }\end{array}$ & $\checkmark$ & $\checkmark$ \\
\hline The home page is long & $\checkmark$ & $\checkmark$ \\
\hline Scrolling a page is a difficult task & $\checkmark$ & $\checkmark$ \\
\hline Unclear to go back to the home page & & $\checkmark$ \\
\hline $\begin{array}{l}\text { Lots of different colours in the default page } \\
\text { background }\end{array}$ & $\checkmark$ & $\checkmark$ \\
\hline $\begin{array}{l}\text { The main and result page view is slightly } \\
\text { unstructured }\end{array}$ & $\checkmark$ & $\checkmark$ \\
\hline The setting menu is complex. & & $\checkmark$ \\
\hline
\end{tabular}

Despite some participants being less experienced Internet users, all participants could successfully complete at least five out of seven search tasks during the search sessions. Also, it was noticed that the number of tasks performed by the more experienced participants differed significantly from those done by less experienced in this field.

The majority of issues stemmed from a lack of understanding of the basic web structure (using the back button to go to the main page) and using standard interaction styles (typing a query into the search box without concentrating and expecting the request to be completed without clicking on the search button). These issues appeared to perplex new users; they were more annoying. The expectation that these issues will arise due to a lack of practice with standard interaction elements and the expectation that the problems will be less with the experience. These issues can also be alleviated by interface design solutions, which will be discussed later.

The results of the usability tests were analyzed to create a list of the issues discovered through the observational technique and open-ended questions. Then, a new solution for the prototype was proposed. The following go over the problems that were discovered:

1) Button size: For a user-friendly interface, bigger button sizes have greater significance. The button size of the main navigation links and the home page is intended to be an important standard because the on-screen button size has a greater effect on interacting speed and communication accuracy. The clicking accuracy with a target diameter of 64pixels was significantly better than on 32-pixel targets for elders.

2) Font size: Also, font size is another major problem needed to be considered. Fancy font types with font sizes below 14 cause loss of clarity for the elderly people in accessing, and these findings are in line with previous research [41]. Therefore, the utility will be more effective if the font size chosen is at the size of 18 pts.

3) Searching ways: There are common ways of searching in use: searching by text, searching by voice, and searching by image. There is a misunderstanding between searching by voice, text, and image by elderly users. They should be separated from each other with enough space and recognized with the button. Also, the button should be having a recognized name or logo to show the differences between them.

4) Home page length: Page scrolling is a complex task for aged people as they require using drag-and-drop or mouse scrolling. Also, they have reduced memory capability than the younger. So, while scrolling the lengthy home page, the contents on the first screen couldn't be recalled, and they got confused. Hence, for older people, if the page length is within one screen, it would be better than having 2 to 3 screens. For aged ones, it would be easier if the average quantity of associated results exposed on the screen was around 5 to 7 .

5) Backtracking support: The use of the back button to return to the home page or previous results page after seeing 
the result document generates a lot of confusion among elderly users since they don't grasp the web's structure and can't tell the difference between the back and forward and home buttons. Elderly users frequently misunderstand the back button on a browser or a webpage, resulting in returning to the same page. These conditions cause elderly users to be unable to distinguish between the functions of each button. Every time an elderly user clicked on the forward, back, or home buttons, they needed some assistance from their moderators to confidently click on them and avoid being lost. These findings are consistent with Cioara et al.'s study [42]. For elderly users, it would be preferable if the search result were displayed in a separate tab or window, allowing them to go to the webpage they desired quickly. It is also quite beneficial if the pop-up window is smaller than the existing window since it allows them to return to the original window by simply clicking on it.

6) Colour contrast of foreground and background objects: Because of aging, elderly users cannot precisely distinguish colour variations like pink, magenta, and purple. Suppose the scenario rises for clicking the particular colour button to move on to the next. In that case, the aged people could not perform well, as their retina could not clearly support the vision to differentiate the color variations. This may lead to mistakes and errors while browsing, and this reduces the search accuracy. Also, the color contrasting of the foreground and the background objects is a major problem, i.e., if the texts in the light background are dim, then it would be hard for the older user to read and proceed further because their vision would not support with age. The web page layout with an off-white background and a high contrast text over a pale background is easy for the older to read.

7) Menu: The observation results found that elderly users are confused by the Hamburger menu and Dropdown menu. Pull-right menus are also challenging for elderly people to navigate, and they frequently have to make multiple attempts before even being able to choose their preferred option. Thus, simpler menus are healthier choices, such as the Classic navigation menu and Sidebar menu.

8) Search results: Search results refer to the list created by search engines in response to a query. Today's search results also include sponsored search results. In addition, the search results also show Related Searches, People Also Search For, People Also Ask, and Top Stories etc. Because of that, elderly people misunderstand these suggested results. For the elders, the view of less is more, so natural search results returned by the search engine's internal evaluation algorithm based on relevancy are better suited and do not include any other results.

9) Result page view: Because users do not often process search results in a logical order, today's search-results pages could have a wide range of layouts. They use the pin-ball pattern to distribute their attention more evenly across the page than in the past. Images, video, embedded text content, and even interactive features are frequently included in today's search engine results pages. Any given search can yield a wide variety of visual elements. The variety of information and presentation is crucial in shifting user attention throughout the SERP [43]. To make it easier for the elderly to find the information, they need a simple list of less than ten blue links, each neatly packaged with a URL, blue link, and text snippet.

\section{Results of System Usability Scale (SUS)}

In a test between two web search interfaces, randomly 15 users worked with two web search user interfaces (Google and Bing). They conducted seven different tasks on both interfaces before completing the ten-item SUS questionnaire [44], with the findings provided in Table III. (The difference score is calculated by subtracting the Bing interfaces score from the Google interfaces score) [45].

TABLE III. PAIRS OF SYSTEM USABILITY SCALE SCORES AND THEIR DIFFERENCES

\begin{tabular}{|l|l|l|l|}
\hline Participant & Google interface & Bing Interface & Differences \\
\hline 1 & 77.5 & 72.5 & 5 \\
\hline 2 & 67.5 & 65 & 2.5 \\
\hline 3 & 70 & 65 & 5 \\
\hline 4 & 65 & 57.5 & 7.5 \\
\hline 5 & 65 & 32.5 & 32.5 \\
\hline 6 & 80 & 72.5 & 7.5 \\
\hline 7 & 70 & 67.5 & 2.5 \\
\hline 8 & 77.5 & 65 & 12.5 \\
\hline 9 & 70 & 70 & 0 \\
\hline 10 & 77.5 & 67.5 & 10 \\
\hline 11 & 80 & 70 & 10 \\
\hline 12 & 77.5 & 75 & 2.5 \\
\hline 13 & 75 & 75 & 0 \\
\hline 14 & 70 & 67.5 & 2.5 \\
\hline 15 & 80 & 75 & 5 \\
\hline Mean & 73.5 & 66.5 & 7 \\
\hline
\end{tabular}

To measure aspects related to interface usability, by using the SUS questionnaire [46], created by John Brooke in 1996 [47] with the minor modifications by Finstad [46] in 2006. It is a versatile and quick method that is extensively used to assess the system's usability.

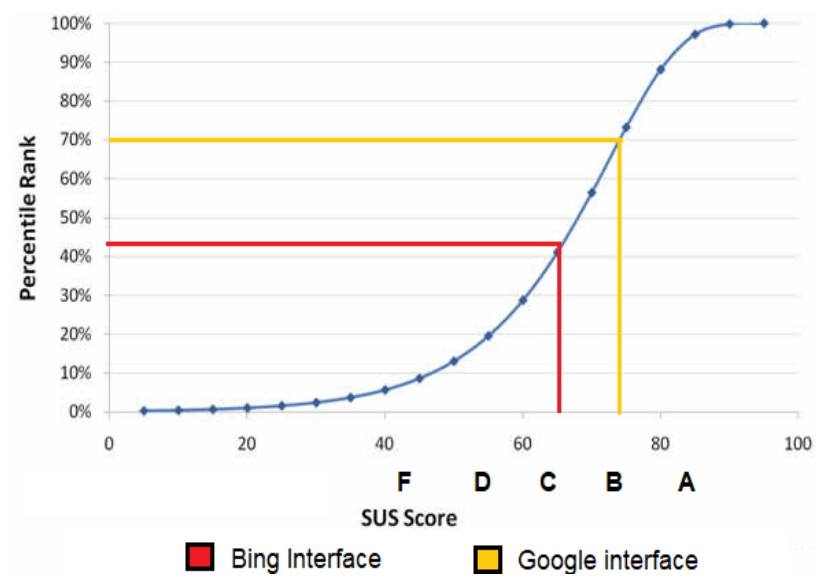

Fig. 2. Percentile Rankings of SUS Scores from between Bing Interface and Google Interface. 
The SUS mark in Google Interface was estimated as 73.5, which is more than the average of 68, and the SUS mark in Bing Interface was 66.5, which is less than the average of 68 . The results of the SUS are presented in Table III. In addition, the percentile rank recommended by Sauro in 2012 [40] was mapped to the measured SUS score, and the percentage was determined, as shown in Fig. 2. The SUS score of Bing is equivalent to $45 \%$ or grade $\mathrm{C}+$, and the SUS score of Google Interface is equivalent to $69 \%$ or grade $\mathrm{B}+$.

Following the score analysis recommended by Bangor et al. in 2009 [48], the usability of the Google Interface is valued as "Good", and the usability of the Bing Interface is valued as "Ok" (see Fig. 3). As a result, the usability level of the UI is considered to be difficult. However, it may not be said that the usability of the interface is poor.

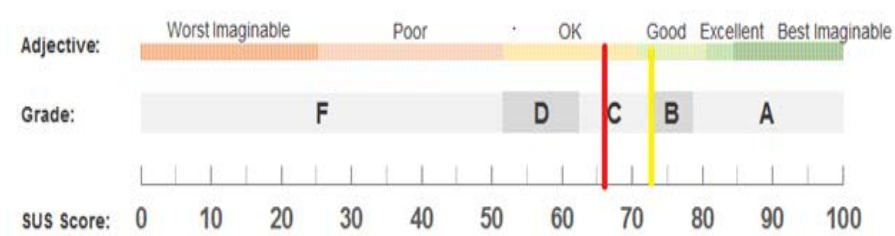

Google Interface Bing Interface

Fig. 3. Mapping the SUS Score on the Bangor \& AL (2009) Interpretation Diagram.

According to Lewis and Sauro in 2009 [49], the learnability score of a system can be calculated individually from usability as the second aspect of SUS, as presented in Fig. 4.

Learnability $=($ item $10+$ item 4$) * 12.5$

Usability = sum of Item $(1,2,3,5,6,7,8,9) * 3.125$

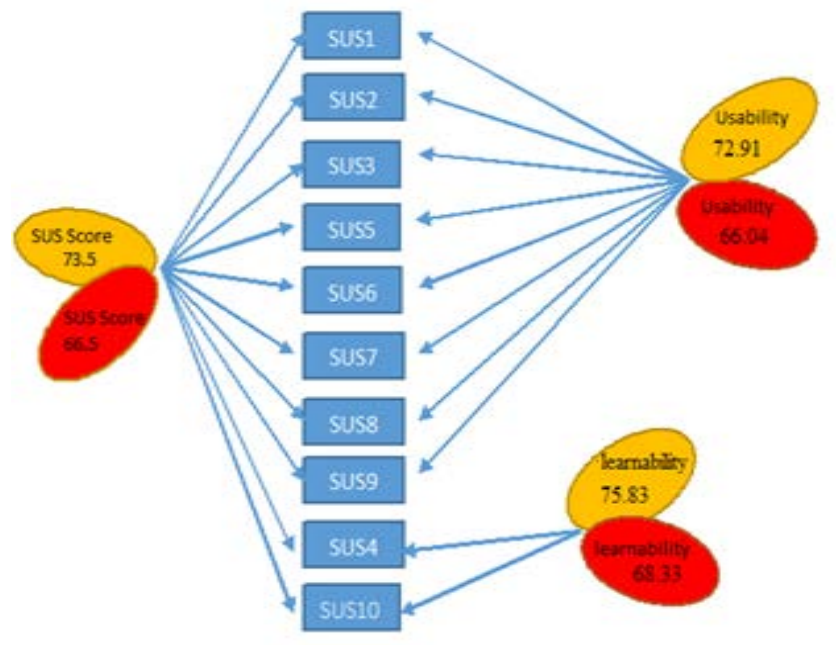

Google Interface Bing Interface

Fig. 4. Illustrate Usability, SUS Score and Learnability.

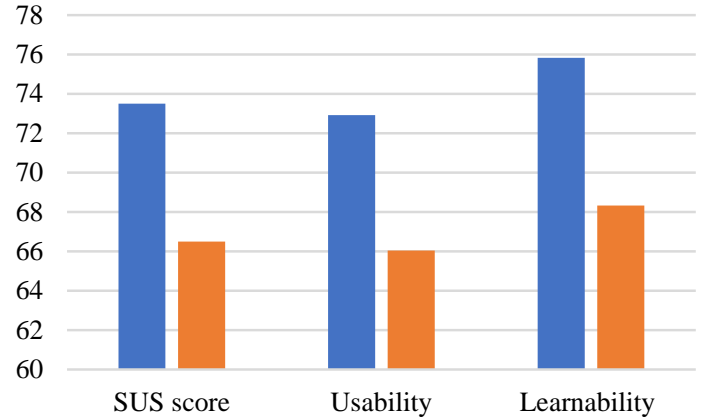

Fig. 5. Google Interface and Bing Interface and their Usability and Learnability Differences.

According to the collected data, the Google UI has a learnability score of 75.83, whereas the Bing UI has 68.33. They are remarkably low than the usability score in both interfaces, which was 72.91 and 66.04, as shown in Fig. 4. As a result, the usability level for the Bing interface is lower than the learnability level. It is rated as OK, whereas the usability level for the Google interface is virtually Good. Clearly, greater thought should be given to the factors that influence usability during the design process.

From Fig. 5, it is observed that the usability score of the Google interface is greater than that of the Bing interface, with the mean value of 72.91 and 66.04, respectively. This shows that the Google interface is more user friendly for elderly people compared with the Bing interface.

The paired t-test (often called the paired-samples t-test) compares the average of two related groups to see if they differ statistically significantly [45]. The results of the paired-samples t-test obtained using SPSS software are shown in Tables IV, Table V, and Table VI.

TABLE IV. GOOGLE AND BING SUS PAIRED SAMPLES StATISTIC

\begin{tabular}{|l|l|l|l|l|}
\hline Pair 1 & Mean & N & Std. Deviation & Std. Error Mean \\
\hline Google_SUS & 73.5000 & 15 & 5.49350 & 1.41842 \\
\hline Bing_SUS & 66.5000 & 15 & 10.55597 & 2.72554 \\
\hline
\end{tabular}

TABLE V. GOOGLE AND BING SUS PAIRED SAMPLES CORRELATION

\begin{tabular}{|l|l|l|l|}
\hline Pair 1 & N & Correlation & Sig. \\
\hline Google_SUS \& Bing_SUS & 15 & .696 & .004 \\
\hline
\end{tabular}

TABLE VI. GoOgle ANd Bing SUS Paired SAMPLES Test

\begin{tabular}{|c|c|c|c|c|c|c|c|c|}
\hline \multirow{3}{*}{ Pair 1} & \multirow{3}{*}{ Mean } & \multicolumn{4}{|c|}{ Paired Differences } & \multirow{3}{*}{ t } & \multirow{3}{*}{$d f$} & \multirow{3}{*}{$\begin{array}{l}\text { Sig. } \\
\text { (2-tailed) }\end{array}$} \\
\hline & & \multirow[t]{2}{*}{ Std. Deviation } & \multirow{2}{*}{$\begin{array}{l}\text { Std. } \\
\text { Error } \\
\text { Mean }\end{array}$} & \multicolumn{2}{|c|}{$\begin{array}{l}95 \% \text { Confidence } \\
\text { Interval of } \\
\text { the Difference }\end{array}$} & & & \\
\hline & & & & Lower & Upper & & & \\
\hline $\begin{array}{l}\text { SUS of } \\
\text { Google } \\
\& \\
\text { Bing }\end{array}$ & 7.0 & 7.80339 & 2.01483 & 2.67863 & 11.32137 & 3.474 & 14 & .004 \\
\hline
\end{tabular}


A test statistic (t) is equal to 3.474. The p-value is used to determine whether this is significant or not. Because this is a two-sided test, the result is significant at $\mathrm{p}<.05$.

In this study, the p-value is $=0.004$ and the p-value is $<0$ .05. This value is too small, which mean that there is less than one in a billion chances that the means SUS scores are equal to each other. We can also conclude that it can be over $99.6 \%$ sure that the Google and Bing interfaces have different SUS scores. Google interface's SUS score of 73.5 is statistically higher than Bing interfaces of 66.50. Also, the Google interface shows a reduced standard mean error rate of 1.41842 compared to the Bing interface (2.72554). So, it can be concluded that elderly users perceived the Google interface as easier to use than the Bing interface.

\section{Discussion}

In both Google and Bing, the least experienced users had significantly more usability issues when using the search engines. This shows that practice with search engines is advantageous, if not essential, for efficient search (the same is true for young; see Pollock and Hockley) [50].

In Google, the most frequent ease of use issue was with the usage of smaller fonts for buttons and explanation as the participants were not able to focus and understand the text written to bring the mouse over and click them properly. The user can change the size of the text on well-designed websites on their own. However, without resizing the entire page, which can be done using the browser's zoom, the text boxes and the font used inside the boxes cannot be resized well. As a result, to make searching easier for people with low vision, text boxes and fonts should be larger or, at the very least, resized as the text size is increased. It would be easier for elderly users to modify their queries if the font was larger and the gaps between letters were wider.

Another reason for the smaller font size concerns in Google and Bing is unquestionably the participants' lack of knowledge with the keyboard (e.g., both the Backspace button and Delete button confused participants) and the mouse (e.g., keeping the mouse still while clicking). Nonetheless, age-related psychomotor issues additionally added to this issue by making it harder to perform fine motor movements, particularly when the target text or button is small (e.g., when attempting to situate the cursor between two letters). Bigger textual style, bigger letter spacing and "clear content-box" buttons may help the elderly participants better as these would help focus them on the target with the cursor easily. Besides that, adding a clear button to clear the text box query with one click may help them to reduce using Backspace and Delete buttons.

Similar to Aula and kaki, many participants often had problems due to a lack of knowledge of the web's structure [19, 26]. Even though the participants understood the basic working of the back button, they could not get back to the first search page after following the result pages one after another. This outcome demonstrates that the Internet browser interfaces may not be as natural as Kubeck et al. [51] introduced. Some preplanning may be necessary to make the initial browsing experience less perplexing. Opening the results in a new web browser or in browsers that allow tabbed browsers to open in new tabs might remedy the issues stated above. This technique keeps the main results page of the web search, allowing users to view back the results from there.

Apart from this, the many advanced functionalities of Google and Bing, like advanced search, search tools, language setting etc., confused the participants. Thus, aiming to provide older adults with a simple, easy-to-use interface would be more beneficial. Advanced searching can be thought of as an option for experienced users. Some participants accidentally clicked it and were confused with its working and couldn't get back to the basic search page without assistance. Thus, it's better to altogether avoid the advanced search option. However, the language option seems more important for those users who are not well acquainted with English, and so it's recommended to have the language option.

Participants in both Google and Bing frequently neglect to focus and click into the search text box before typing in the search text box, which is a widespread problem. The only visible difference between having the cursor on top of the search text box and really having the focus on the text box is whether or not the cursor blinks. You can type text into the search text box if it blinks. This indication is clearly insufficient for people with reduced vision as the elderly are more concentrated on the keyboard while typing than on the screen. To alleviate this problem when the search text box is off-focus, Aula et al. made the focused feedback increasingly via greying the search text box and the text and provided a thick border and black highlighted text whenever the focus was in the search text box [26]. When the user types without focusing on the search text box, an attention sound is recommended. Furthermore, some volunteers placed the mouse cursor on top of the search text box before attempting to edit the search query but then failed to press the click to move the focus to the search text box. Thus, the suggestion is similar to Aula et al. [26], which to grey the search text box and the button when the cursor is not in the text box and also to have a tooltip with the text "Click the mouse button to insert text" when the mouse pointer is above the text box.

In many cases, it was seen that the users started searching their queries within the resultant websites without even realizing that they had left the search engine. As an outcome, they came up with better new queries inside the site search but received no results. After being indicated to attempt the inquiry again utilizing a search engine, they could find the results. Thus, with better training regarding the web search engine, the participants would probably be more at ease in using the search engine.

In Google and Bing, information related to the previously visited search results is saved at the history menu and also bookmarked results are saved in the browser. Thus, participants faced difficulties going back to previously visited results and bookmarked results in different browsers. Because each browser has its way to bookmark results and save the history browsing, it would be better to design Bookmark and History menus in the main page interface as part of interface elements to solve this confusion. So whatever browser was used, all UI elements is still the same, and the bookmark and history menus will be loaded with when opened by any browser. 
Occasionally, information from a previous search was mixed with information from a recent Google and Bing engine search. Thus, after typing in a new query and noticing a wrong result list, participants wanted to get back to the original search page, but they did not know how to. It would be better to provide users with a clear starting point for new searches to alleviate this confusion. Thus, a separate "Begin new search" button is recommended to clear all the information about the previous searches $[19,26]$ and provide a natural starting point for new search tasks.

\section{SUGGested SOLUTION}

This study discovered that a simple design tends to make the search experience for elderly people less troublesome and more manageable. Many participants also expressed that search interfaces with all their different colours seemed messy and complex. It's recommended that the improved search engine for elders use colours sparingly.

The goal of the improved search engine interface is not to displace more complicated systems, but to provide elderly people with the option of using a basic search engine, personalized and adaptable interface and easy-to-use interface for using the web for their daily Internet searching to overcoming their weak intellectual and physical abilities, as well as their cognitive abilities.

Table VII presents suggested improvements to design a usable web search user interface for elderly users based on the elderly users' major problems during interacting with both interfaces.

The suggested elderly web search interface for the elderly community is based on the finding from the experimental results of Both Google and Being interface from the elderly perspective and previous studies. In addition to the original features of existing search interfaces, the new web search user interface for elderly users allows customization towards the users' wishes. According to Peter Brusilovsky and Maybury [52, 53], the adaptation of user interface for web applications could be in the areas given below:

Content selection: The presentation of contents in the user interface to users.

1) Information presentation: Visual presentation of every piece of information is in the interface.

2) Concepts of navigation: Navigation through the user interface by the users for gathering their desired information given in the webpage.

In order to achieve a coherent design between different variations, we suggest fixing the positions of different SUI parts. Fig. 6 depicts the general structure of the suggested search UI for the elderly. It consists of eight groups of elements: a setting section, a help section, login and logout, profile image, a menu for saved bookmarked results with different categories, a history section menu, a theme mode button, the main search results section. The search input consists of elements: text, voice, image with a larger button size and label. Besides adding a clear button to clean text search "query" and begin a new search. A bookmarked menu and history menu provide direct links for the elderly to access certain saved results for ease of use and navigation. A menus support the elderly to save time and effort instead of researching again for the same results and reduce the memory load of the elderly.

TABLE VII. SUGGESTED DESIGN SOLUTIONS BASED ON THE IDENTIFIED USABILITY PROBLEMS

\begin{tabular}{|c|c|}
\hline Usability Problems & Design Solutions \\
\hline $\begin{array}{l}\text { The default font size is still } \\
\text { small. }\end{array}$ & $\begin{array}{l}\text { The default font size is large, and it is constant } \\
\text { in the interface without any change, even if } \\
\text { using a different browser with ease of } \\
\text { modification. }\end{array}$ \\
\hline $\begin{array}{l}\text { The voice search button, the } \\
\text { image search button and the } \\
\text { text search button are small } \\
\text { and close to each other. }\end{array}$ & $\begin{array}{l}\text { They should be separated from each other with } \\
\text { enough space and recognized with a button. } \\
\text { Also, the button should be having a recognized } \\
\text { name or logo to show the differences between } \\
\text { them. }\end{array}$ \\
\hline The home page is long & Reduce the length of the home page \\
\hline $\begin{array}{l}\text { Scrolling a page is a difficult } \\
\text { task }\end{array}$ & $\begin{array}{l}\text { Reduce the length of the home page at most one } \\
\text { screen and half }\end{array}$ \\
\hline $\begin{array}{l}\text { Unclear to go back to the } \\
\text { home page }\end{array}$ & $\begin{array}{l}\text { Make the results open in a new window and that } \\
\text { can be clear to go back to the main home page. }\end{array}$ \\
\hline $\begin{array}{l}\text { Lots of different colours are } \\
\text { on the page background. }\end{array}$ & $\begin{array}{l}\text { The background is unchangeable and to be } \\
\text { white or with clear color with font dark. }\end{array}$ \\
\hline $\begin{array}{l}\text { The main and result page } \\
\text { view is slightly unstructured }\end{array}$ & $\begin{array}{l}\text { Restructure it to show all UI elements on the } \\
\text { main page }\end{array}$ \\
\hline The setting menu is complex. & $\begin{array}{l}\text { Reduce the elements of the setting that do not } \\
\text { affect the main job of the interface. Thus, the } \\
\text { simpler menus are healthier choices, such as the } \\
\text { Classic navigation menu and Sidebar menu. }\end{array}$ \\
\hline \begin{tabular}{|l|} 
Difficult to go back to \\
previous open results and \\
bookmarked results in \\
different browsers. That is \\
because each browser has its \\
way to bookmark results and \\
save the history browsing.
\end{tabular} & $\begin{array}{l}\text { Bookmark and result History should be put in } \\
\text { the main home interface. So whatever browser } \\
\text { was used, all UI elements is still the same, and } \\
\text { the bookmark and history will be loaded with } \\
\text { when opened by any browser. }\end{array}$ \\
\hline A large number of results & $\begin{array}{l}\text { Reduce the view search results on the screen to } \\
\text { be } 5 \text { to } 7 \text { on each screen. }\end{array}$ \\
\hline $\begin{array}{l}\text { Misunderstanding suggested } \\
\text { results such as People Also } \\
\text { Search For and Related } \\
\text { Searches. }\end{array}$ & Remove it \\
\hline
\end{tabular}




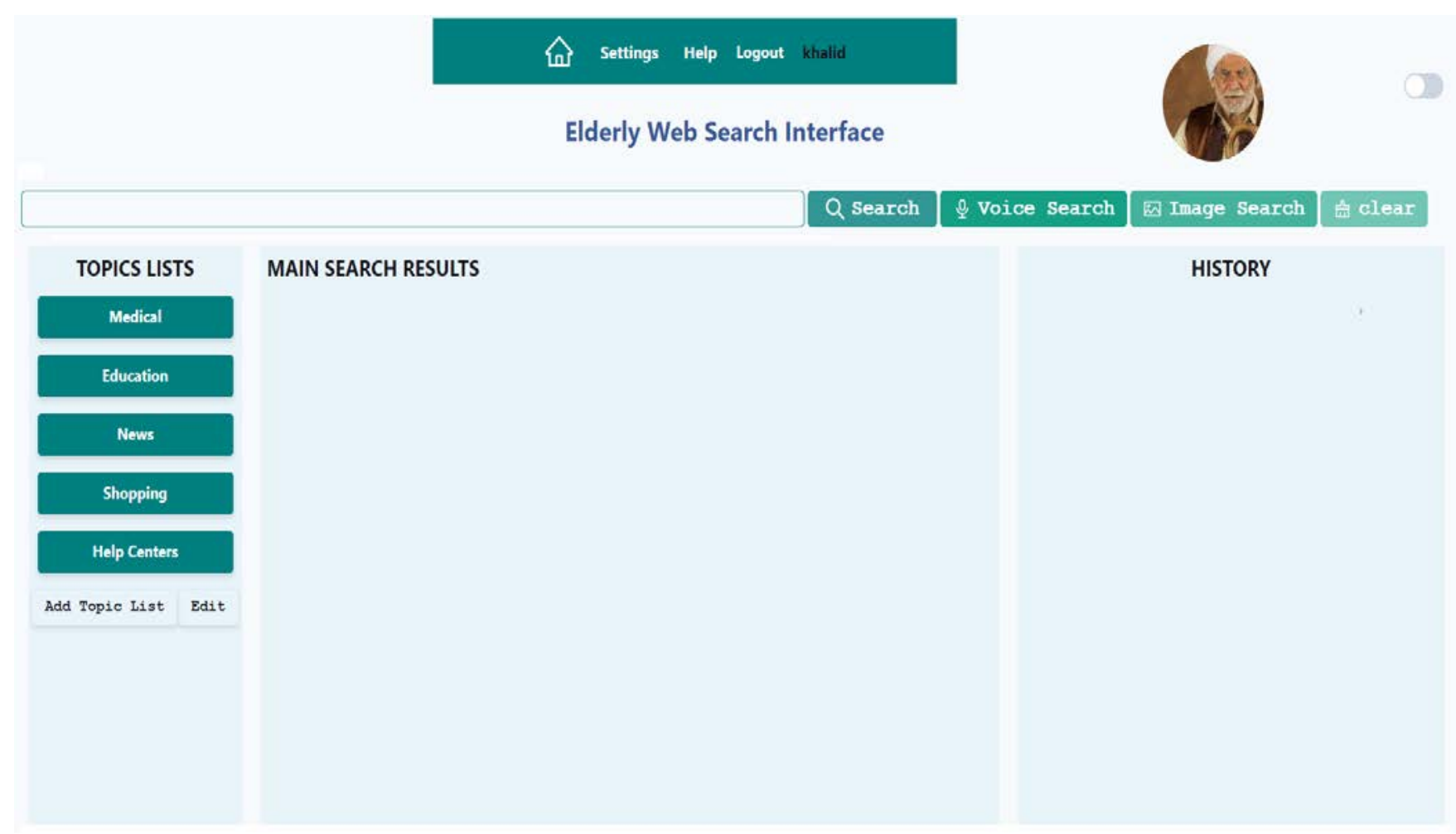

Fig. 6. The General Structure of the Suggested Search user Interface for Elderly.

\section{VII.CONCLUSION}

This research conducted usability evaluations of Google and Bing interfaces from the perspectives of elderly users and suggested how developers can better improve search engine interfaces to make them more usable to elderly users. Applying an observational evaluation technique and SUS questionnaire in this research was shown to be effective in identifying a large proportion of usability problems elderly users faced while interacting with web search UIs. The results show that the Google interface is much better than the Bing interface because it is more user-friendly and simplified to use. It has a larger button size and font size, reduced home page length, larger letter spacing, and visible content-box buttons that would assist the elderly better since it helps them easily focus on the target through the cursor. Also, the Google interface is more suitable for the intellectual ability of the elderly that includes their memory and learning capacity, technical knowledge and experience in using the computers. Moreover, it shows good usability and learnability with a higher SUS score than the Bing user interface. Therefore, the usability level is lower than the learnability level for the Google Interface and the Bing interface, and it is obvious that it should be paid more attention to the elements influencing usability during the design process.

Simple interfaces and simple result pages benefit elderly users by reducing issues produced by not understanding what is happening, reducing the total number of features to be learned, and, most importantly, making the users feel in control of the situation. Aside from that, it is recommended that a "clear text box query" button be added to avoid misunderstandings in using the Backspace and Delete buttons. Furthermore, the needs of senior users varied. Therefore interfaces should be adaptive and personalized for each user to match their individual requirements.

In light of the findings of this study, specifically the design solutions, a prototype of a web search user interface will be designed as future work. The prototype will be put through its paces with elderly volunteers. The elderly volunteers' interactions with the prototype while executing various tasks and their feedback from a think-aloud helped develop the prototype. The improved prototype can then be used to create a commercially viable web search user interfaces launcher.

\section{ACKNOWLEDGMENT}

Malaysia's Ministry of Higher Education (MOHE), Libya's Ministry of Higher Education, and the University of Gharyan all contributed to this work. We would like to thank the Universiti Teknologi Malaysia (MOHE) and the UTM VicubeLab research group.

\section{REFERENCES}

[1] Allah, Khalid Krayz, Nor Azman Ismail, and Mohamad Almgerbi. "Designing web search UI for the elderly community: a systematic literature review." Journal of Ambient Intelligence and Humanized Computing, 1-25, 2021.

[2] Sanchiz, Mylene, Jessie Chin, Aline Chevalier, Wai-Tat Fu, Franck Amadieu, and Jibo He. "Searching for information on the Web: Impact of cognitive aging, prior domain knowledge and complexity of the search problems." Information Processing \& Management 53, no. 1, 281-294, 2017.

[3] Wagner, N., Hassanein, K., \& Head, M. The impact of age on website usability. Computers in Human Behavior, 37, 270-282. https://doi.org/10.1016/j.chb.2014.05.003, 2014.

[4] Sanchiz, M., et al. "User-friendly search interface for older adults: supporting search goal refreshing in working memory to improve 
information search strategies." Behaviour \& Information Technology, 116, 2019.

[5] Miyake, Asuka, Yuji Morinishi, and Masahiro Watanabe. "Estimation Models of User Skills Based on Web Search Logs." International Conference on Human-Computer Interaction. Springer, Cham, 2016.

[6] Salman, Hasanin Mohammed, Wan Fatimah Wan Ahmad, and Suziah Sulaiman. "Usability Evaluation of the Smartphone User Interface in Supporting Elderly Users from Experts' Perspective." Ieee Access 6: 22578-91, 2018.

[7] Fisk, Arthur D., Sara J. Czaja, Wendy A. Rogers, Neil Charness, and Joseph Sharit. Designing for older adults: Principles and creative human factors approaches. CRC press, 2020.

[8] Sanchiz, Mylene, et al. "Searching for information on the web: Impact of cognitive aging, prior domain knowledge and complexity of the search problems." Information Processing \& Management 53.1 281-294, 2017.

[9] Chevalier, Aline, Aurélie Dommes, and Jean-Claude Marquié. "Strategy and accuracy during information search on the Web: Effects of age and complexity of the search questions." Computers in Human Behavior 53 (2015): 305-315, 2015.

[10] Chin, Jessie, and Wai-Tat Fu. "Interactive effects of age and interface differences on search strategies and performance." In Proceedings of the SIGCHI Conference on Human Factors in Computing Systems, pp. 403412. 2010.

[11] Nivala, Annu-Maaria, Stephen Brewster, and L. Tiina Sarjakoski. "Usability Evaluation of Web Mapping Sites." In Landmarks in Mapping, pp. 239-256. Routledge, 2014.

[12] Barnum, Carol M. Usability testing essentials: ready, set... test!. Morgan Kaufmann, 2020.

[13] Chiew, Thiam Kian. "A systematic literature review of the design approach and usability evaluation of the pain management mobile applications." Symmetry 11, no. 3, 400, 2019.

[14] Bačíková, Michaela, Jaroslav Porubän, Matúš Sulír, Sergej Chodarev, William Steingartner, and Matej Madeja. "Domain Usability Evaluation." Electronics 10, no. 16 (2021): 1963, 2021.

[15] Ivory, Melody Y., and Marti A. Hearst. "The state of the art in automating usability evaluation of user interfaces." ACM Computing Surveys (CSUR) 33, no. 4, 470-516, 2001.

[16] Jessie Chin and Wai-Tat Fu, "Interactive Effects of Age and Interface Differences on Search Strategies and Performance." ACM, 2010.

[17] Boot, W., Charness, N., Czaja, S.J. and Rogers, W.A. Designing for older adults: Case studies, methods, and tools. CRC Press, 2020.

[18] Sauro, Jeff, and James R. Lewis. 2011. "When Designing Usability Questionnaires, Does It Hurt to Be Positive?" Conference on Human Factors in Computing Systems - Proceedings, 2215-23, 2011.

[19] Aula, Anne. "User study on older adults' use of the Web and search engines." Universal Access in the Information Society 4, no. 1, 67-81, 2005.

[20] Kobayashi, M., Hiyama, A., Miura, T., Asakawa, C., Hirose, M. and Ifukube, T. September. "Elderly user evaluation of mobile touchscreen interactions". In IFIP conference on human-computer interaction (pp. 83-99). Springer, Berlin, Heidelberg, 2011.

[21] Dolničar, V., Šetinc, M. and Petrovčič, A. "Toward an age-friendly design of smartphone interfaces: The usability test of a launcher for older adults ". Uporabna Informatika, XXIV, 24, pp.4-15, 2016.

[22] Salman, H.M., Ahmad, W.F.W. and Sulaiman, S., "Usability evaluation of the smartphone user interface in supporting elderly users from experts' perspective " Ieee Access, 6, pp.22578-22591, 2018.

[23] Di Nuovo, A., Broz, F., Belpaeme, T., Cangelosi, A., Cavallo, F., Esposito, R. and Dario, P., October. VA web based multi-modal interface for elderly users of the robot-era multi-robot service ". In 2014 IEEE international conference on Systems, Man, and Cybernetics (SMC) (pp. 2186-2191). IEEE, 2014.

[24] Patsoule, E. and Koutsabasis, P., "Redesigning websites for older adults ": a case study. Behaviour \& Information Technology, 33(6), pp.561573, 2014.

[25] Haesner, M., Wolf, S., Steinert, A. and Steinhagen-Thiessen, E. "Touch interaction with Google Glass-Is it suitable for older adults?
". International Journal of Human-Computer Studies, 110, pp.12-20, 2018.

[26] Aula, A. and Käki, M. "Less is more in Web search interfaces for older adults ". First Monday, 2005.

[27] Cornet, V.P., Daley, C.N., Srinivas, P. and Holden, R.J., September. "User-centered evaluations with older adults: testing the usability of a mobile health system for heart failure self-management ". In Proceedings of the Human Factors and Ergonomics Society Annual Meeting (Vol. 61, No. 1, pp. 6-10). Sage CA: Los Angeles, CA: SAGE Publications, 2017.

[28] PREECE, J., ROGERS, Y., \& PREECE, J. "Interaction design: beyond human-computer interaction ". Chichester, Wiley, 2019.

[29] Joe, J., Chaudhuri, S., Le, T., Thompson, H. and Demiris, G. "The use of think-aloud and instant data analysis in evaluation research: Exemplar and lessons learned ". Journal of biomedical informatics, 56, pp.284291, 2015.

[30] J. R. Lewis, "Usability: Lessons Learned. and Yet to Be Learned," Int. J. Hum. Comput. Interact., vol. 30, no. 9, pp. 663-684, 2014, doi: 10.1080/10447318.2014.930311.

[31] P. Corti, B. Lewis, and A. T. Kralidis, "Hypermap registry: an open source, standards-based geospatial registry and search platform," Open Geospatial Data, Softw. Stand., vol. 3, no. 1, p. 8, Dec. 2018, doi: 10.1186/s40965-018-0051-x.

[32] D. Pal and V. Vanijja, "Perceived usability evaluation of Microsoft Teams as an online learning platform during COVID-19 using system usability scale and technology acceptance model in India," Child. Youth Serv. Rev., vol. 119, p. 105535, 2020, doi: 10.1016/j.childyouth.2020.105535.

[33] J. Sauro and J. R. Lewis, "Correlations among prototypical usability metrics: Evidence for the construct of usability," Conf. Hum. Factors Comput. Syst. - Proc., no. August, pp. 1609-1618, 2009, doi: 10.1145/1518701.1518947.

[34] M. K. Othman, A. Nogoibaeva, L. S. Leong, and M. H. Barawi, "Usability evaluation of a virtual reality smartphone app for a living museum," Univers. Access Inf. Soc., no. 0123456789, pp. 9-13, 2021, doi: 10.1007/s10209-021-00820-4.

[35] A. Bangor, P. T. Kortum, and J. T. Miller, "An empirical evaluation of the system usability scale," Int. J. Hum. Comput. Interact., vol. 24, no. 6, pp. 574-594, 2008, doi: 10.1080/10447310802205776.

[36] A. Bangor, T. Staff, P. Kortum, J. Miller, and T. Staff, "Determining what individual SUS scores mean: adding an adjective rating scale," J. usability Stud., vol. 4, no. 3, pp. 114-123, 2009.

[37] J. R. Lewis Senior HF Engineer and J. Sauro, "Revisiting the Factor Structure of the System Usability Scale," J. Usability Stud., vol. 12, no. 4, pp. 183-192, 2017.

[38] S. Borsci, S. Federici, S. Bacci, M. Gnaldi, and F. Bartolucci, "Assessing User Satisfaction in the Era of User Experience: Comparison of the SUS, UMUX, and UMUX-LITE as a Function of Product Experience," Int. J. Hum. Comput. Interact., vol. 31, no. 8, pp. 484-495, 2015, doi: 10.1080/10447318.2015.1064648.

[39] T. S. Tullis and J. N. Stetson, "A Comparison of Questionnaires for Assessing Website Usability ABSTRACT: Introduction," Usability Prof. Assoc. Conf., pp. 1-12, 2004, [Online]. Available: http://home.comcast.net/ tomtullis/publications/UPA2004TullisStetson. pdf.

[40] Jeff Sauro and James R. Lewis. "Standardized Usability Questionnaires. Quantifying the User Experience" , 2012. https://doi.org/10.1016/b9780-12-384968-7.00008-4.

[41] Rot, A., Kutera, R., Gryncewicz, W. Design and assessment of user interface optimized for elderly people. A case study of actgo-gate platform, in: ICT4AWE 2017 - Proceedings of the 3rd International Conference on Information and Communication Technologies for Ageing Well and e-Health. SciTePress, pp. 157-163, 2017. doi:10.5220/0006320001570163.

[42] Cioara, T., Anghel, I., Valea, D., Salomie, I., Martin, V.S., Marchena, A.G., Jimeno, E. and Vastenburg, M. Adaptive workspace interface for facilitating the knowledge transfer from retired elders to start-up companies. In Ambient Assisted Living and Enhanced Living Environments (pp. 287-309). Butterworth-Heinemann, 2017. 
[43] Moran, K. and Goray, C. "Complex Search-Results Pages Change Search Behavior: The Pinball Pattern ", 2019.

[44] Lewis Senior HF Engineer, James R, and Jeff Sauro. "Revisiting the Factor Structure of the System Usability Scale." Journal of Usability Studies 12 (November): 183-92, 2017.

[45] auro, Jeff, and James R Lewis. Quantifying the User Experience, Second Edition: Practical Statistics for User Research. ACM SIGSOFT Software Engineering Notes, 2016.

[46] Finstad, Kraig. "The system usability scale and non-native English speakers." Journal of usability studies 1, no. 4: 185-188, 2006.

[47] Brooke, John. 1996. "SUS: A 'Quick and Dirty' Usability Scale." Usability Evaluation In Industry, no. November 1995: 207-12, 2006. https://doi.org/10.1201/9781498710411-35.

[48] Bangor, Aaron, Technical Staff, Philip Kortum, James Miller, and Technical Staff. "Determining What Individual SUS Scores Mean: Adding an Adjective Rating Scale." Journal of Usability Studies 4 (3): 114-23, 2009.
[49] Lewis, James R., and Jeff Sauro. "The Factor Structure of the System Usability Scale." Lecture Notes in Computer Science (Including Subseries Lecture Notes in Artificial Intelligence and Lecture Notes in Bioinformatics) 5619 LNCS (August): 94-103, 2009, https://doi.org/10.1007/978-3-642-02806-9_12.

[50] Pollock, A. and Hockley, A. What's wrong with Internet searching. D-lib magazine, 3(3), pp.1-5, 1997.

[51] Kubeck, J.E., FINDING INFORMATION ON THE WORLD WIDE WEB: EXPLORING OLDER ADULTS'EXPLORATION. Educational Gerontology, 25(2), pp.167-183, 1999.

[52] Brusilovsky, Peter, and Mark T. Maybury. "From adaptive hypermedia to the adaptive web." Communications of the ACM 45, no. 5: 30-33, 2002.

[53] Heumader, Peter, Klaus Miesenberger, and Tomas Murillo-Morales. "Adaptive User Interfaces for People with Cognitive Disabilities within the Easy Reading Framework." In International Conference on Computers Helping People with Special Needs, pp. 53-60. Springer, Cham, 2020. 